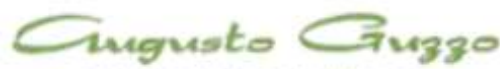

REVISTA ACADEMICA

\title{
Jogos Digitais Brasileiros Para Educação Musical
}

\section{Brazilian Digital Games For Musical Education}

\begin{abstract}
Alan Carvalho
Alan Carvalho é Mestre em Tecnologia, Pós-graduado em Jogos Digitais, em Docência do Ensino Superior e Tecnólogo em Processamento de Dados. Atua na área de Tecnologia da Informação desde 1986 e na área de Educação e Treinamento desde 1989. Autor de livros e materiais de treinamento na área de Tecnologia da Informação. Avaliador do INEP/MEC. Parecerista de cursos da área de Computação para o Guia do Estudante da Editora Abril. Docente e coordenador de cursos de graduação na Fatec São Caetano do Sul e na Faculdade Impacta de Tecnologia. E-mail de contato: alancarv@uol.com.br
\end{abstract}

\section{Resumo}

A partir da constatação de que os jogos representam ferramentas de apoio úteis para os educadores de diversas áreas e que os jogos digitais têm sido cada vez mais considerados nesse contexto, o objetivo deste trabalho foi mostrar como jogos digitais, com ênfase nos desenvolvidos por empresas ou instituições brasileiras, tem sido utilizados na Educação Musical em diversos níveis educacionais, dentro ou fora do sistema formal de educação. Constatou-se por meio de pesquisa bibliográfica e documental haver diversos trabalhos desenvolvidos sobre o tema, além de títulos nacionais de qualidade desenvolvidos por universidades como parte de projetos de pesquisa. Ao mesmo tempo verificou-se que, apesar das empresas brasileiras de desenvolvimento de jogos digitais terem produzido diversos títulos recentemente, não há informações disponíveis com facilidade para que os educadores musicais tenham subsídios suficientes para a escolha de jogos digitais adequados para sua prática pedagógica.

Palavras-chaves: jogo digital, jogo educacional, educação musical, ensino de Música.

\begin{abstract}
From the observation that games represent useful tools to support educators from different areas and that digital games have been increasingly considered in this context, the aim of this work. was to show how digital games, with an emphasis on developed by companies or Brazilian institutions, has been used in music education at various educational levels, within or outside the formal education system. It was found by means of literature and documentary bave developed several works on the subject, as well as national quality titles developed by universities as part of research projects. At the same time it was found that, despite the Brazilian development of digital games companies have produced many titles recently, no information is available with ease so that music educators have sufficient information for choosing appropriate for their teaching digital games.
\end{abstract}

Key words: digital game, educational game, music education, music teaching. 


\section{Introdução}

Os jogos têm sido utilizados há anos por educadores de diversas áreas como ferramentas de apoio às suas atividades, principalmente no âmbito da educação básica, que no Brasil compreende o Ensino Fundamental e o Ensino Médio.

Com o desenvolvimento crescente das tecnologias de informação e comunicação, os jogos digitais (ou videogames, ou ainda jogos eletrônicos) passaram a ser objeto de estudos no Brasil e em outros países no sentido de verificar se e como poderiam adequar-se às necessidades educacionais, servindo de apoio aos educadores, tal qual tem ocorrido com os jogos ditos "analógicos" (os jogos não eletrônicos) (MATTAR, 2010).

A Educação Musical, além de ser parte integrante dos conteúdos curriculares da educação básica brasileira (BRASIL, 2013a; BRASIL, 2013b), tem sido reconhecida como fator de desenvolvimento pessoal nas várias fases da vida humana inclusive nas iniciativas não-formais (CORREA, 2013; CHIARELLI e BARRETO, 2005; GOHN e STRAVACAS, 2010; JANAUDIS, 2010; BALBINOT, 2013; OLIVEIRA, 2013) e, por esse motivo, é natural que jogos (analógicos e digitais) acabem sendo considerados com o intuito de servirem como ferramenta de auxílio aos professores (RAU,
2011; CÓRIA-SABINI e LUCENA, 2004; RIBEIRO, 2008; FIALHO, 2013; MATTAR, 2010; ALVES, 2004; LOPES e OLIVEIRA, 2013; TEIXEIRA, 2013; FERNANDES, 2010).

Assim, o presente trabalho tem por objetivo mostrar como jogos digitais, principalmente os desenvolvidos por brasileiros, tem sido utilizados para o ensino de Música nos diversos níveis educacionais. Optou-se por enfatizar os jogos desenvolvidos por brasileiros (sem, no entanto, ignorar alguns títulos estrangeiros talvez até mais conhecidos) por considerar que os nacionais poderiam ser mais adequados à realidade educacional brasileira, levando em consideração as especificidades da nossa cultura e educação.

Para isso, foi realizada uma pesquisa bibliográfica e documental, passando por livros dedicados ao uso dos jogos - analógicos e digitais - como ferramenta educacional, pela legislação educacional brasileira, que traz contribuições significativas ao ensino de Música nas escolas, e pela apresentação de alguns jogos digitais desenvolvidos por empresas e instituições brasileiras, seja para a educação formal ou não, incluindo a modalidade não presencial (Educação à Distância ou EaD).

Esta pesquisa justifica-se no fato de que existe um crescente interesse na utilização de jogos digitais como ferramentas de apoio ao trabalho pedagógico e que o presente levantamento pode trazer informações para os interessados em jogos digitais para Educação 
Musical sobre alguns dos títulos disponíveis e as iniciativas de pesquisa que vem sendo desenvolvidas, assim como incentivar a indústria brasileira de desenvolvimento de jogos digitais a produzir mais títulos voltados ao tema.

\section{A Educação Musical E O Desenvolvimento Pessoal}

Existem vários estudos acadêmicos que abordam o papel da Música como contribuinte para o desenvolvimento pessoal nas diversas fases da vida. Apenas a título de ilustração, um recente levantamento realizado junto ao Google Acadêmico (http://scholar.google.com) com os termos "educação música" resultou em aproximadamente 16.600 resultados. Quando o termo “educação musical” foi utilizado, foram obtidos aproximadamente 14.200 resultados e para "benefícios música desenvolvimento" chegou-se a 15.300 resultados.

Com o intuito de trazer ao conhecimento do leitor alguns dos possíveis benefícios da Educação Musical, neste trabalho são apresentados alguns exemplos recentes de artigos científicos desenvolvidos por pesquisadores brasileiros e publicados em periódicos, dissertações ou teses de programas de pós-graduação.

Correa (2013) observou os processos de exploração sonoro-musical no cotidiano de bebês e pode constatar a partir de suas brincadeiras a exploração de materiais e de seus próprios corpos na elaboração de sons, construindo de forma autônoma estruturas musicais ou sonoro-musicais. Além disso, destacou o papel que a Música e a Educação Musical podem ter na solidificação do relacionamento entre bebês e pais.

Chiarelli e Barreto (2005) mostram que as atividades de musicalização desenvolvidas na escola contribuem para o autoconhecimento e para a comunicação com o outro, trazendo benefícios no desenvolvimento cognitivo, linguístico, psicomotor e sócio afetivo.

Acrescentam que essas atividades: Não visam a formação de músicos, e sim, através da vivência e compreensão da linguagem musical, propiciar a abertura de canais sensoriais, facilitando a expressão de emoções, ampliando a cultura geral e contribuindo para a formação integral do ser. (CHIARELLI; BARRETO, 2005).

Gohn e Stavracas (2010) destacam a importância da Música como forma de arte que contribui para o desenvolvimento do pensamento criativo, da cognição, da socialização e da cultura, não devendo ser encarada apenas como um apoio às atividades escolares.

As autoras ainda mostram que a abordagem da Música na escola permite o desenvolvimento da percepção sensitiva do aluno em relação aos quatro parâmetros sonoros: a altura, o timbre, a intensidade e a 
duração. Entre os benefícios decorrentes, encontram-se: o favorecimento do controle rítmico-motor, benefícios ao uso da voz falada e cantada, estímulo à criatividade em todas as áreas o desenvolvimento das percepções auditiva, visual e tátil, o aumento da concentração, atenção, raciocínio, memória, associação, dissociação, codificação e decodificação.

No Ensino Superior é possível encontrar relações entre a Música e a formação em nível de graduação como, por exemplo, no trabalho desenvolvido por Janaudis [2010] que estudou a utilização da Música como instrumento de reflexão pelo estudante de Medicina, o que pode contribuir nos esforços empreendidos por diversas instituições de ensino no sentido de uma formação mais humanista nessa área.

Balbinot (2013) mostra em um estudo sobre Educação não-formal e Música como esta favorece o desenvolvimento da sensibilidade do adulto, remete aos sentimentos e a reflexão pessoal, contribui para o desenvolvimento intelectual, social e afetivo das pessoas, sendo muito mais do que um meio de aprendizagem e sim de promoção do desenvolvimento humano em diversas dimensões.

Também para as pessoas que estão na terceira idade é possível observar benefícios, como mostrado no estudo conduzido por Oliveira (2013) que relacionou a Música e a qualidade de vida, constatando que a partir do trabalho vocal houve uma diminuição do estresse e da tensão, aumento da capacidade de memória, aumento do poder de concentração, atenção, imaginação e criatividade, além da importância da Música como instrumento de socialização, melhoria do humor, aumento da motivação e da autoestima, resultando em crescimento interpessoal e afetivo.

Após essa breve apresentação de trabalhos acadêmicos relacionando a Música e o desenvolvimento pessoal nas diversas fases da vida da pessoa, mostra-se importante contextualizar a Educação Musical no Brasil, uma vez que este trabalho aborda o tema.

\section{A Educação Musical No Brasil}

O Parecer CNE/CEB n $n^{\circ}$ 12/2013 (BRASIL, 2013 ), que traz as Diretrizes Nacionais para a operacionalização do ensino de Música na Educação Básica, mostra que o primeiro registro relacionado à Educação Musical na legislação educacional brasileira data de 1854, ainda no Regime Imperial, com o Decreto $\mathrm{n}^{\circ} 1.331$ que trazia as primeiras definições para o ensino de Música nas escolas apesar de estar restrito à cidade do Rio de Janeiro, capital do país à época.

Em 1890 foi publicado o Decreto n ${ }^{\circ}$ 981, que definia o "Regulamento da Instrução Primaria e Secundaria do Districto Federal" (sic), no qual a Música estava incluída como um dos componentes do " $1^{\circ}$ grau" (sic), ministrado para crianças de sete a treze anos. 
Houve entre as décadas de 1930 e 1960 um maior espaço para o canto orfeônico nas escolas a partir da proposta de Heitor VillaLobos, inclusive com a publicação de decretos nos anos de 1931, 1934 e 1942 que trouxeram legitimidade nacional ao tema.

Já nos anos 1960 pode-se dizer que esse espaço conquistado nas décadas anteriores foi diminuído, uma vez que na Lei no 4.024/1961 (a LDB - Lei de Diretrizes e Bases da Educação da época) não havia qualquer menção ao ensino de Música. Essa diminuição de espaço continuou nos anos 1970 com a publicação da nova LDB (Lei no 5.692/1971), que trouxe a definição da "Educação Artística" e o consequente ensino polivalente das artes, debatido nas escolas e apontado como inadequado.

Nos anos 1980 as discussões sobre a Educação Musical foram fortalecidas com o surgimento da pós-graduação em Música no Brasil e com a criação da Associação Nacional de Pesquisa e Pós-Graduação em Música (ANPPOM). Esse fortalecimento continuaria nos anos 1990 com a criação da Associação Brasileira de Educação Musical (ABEM), com a inclusão da Música como conteúdo da educação básica a partir da publicação da atual LDB (Lei $\mathrm{n}^{\circ}$ 9.394/1996) e das Diretrizes Curriculares Nacionais, ainda nessa década.

A partir dos anos 2000, diversas campanhas, grupos de pesquisa e eventos tem sido desenvolvidos com o intuito de fortalecer a presença da Educação Musical como parte dos conteúdos escolares, resultando na mais recente iniciativa nesse sentido, o Parecer $\mathrm{CNE} / \mathrm{CEB} \mathrm{n}^{\circ}$ 12/2013, já citado neste texto.

A Educação Musical é objeto de atenção do Ministério da Educação como parte da formação escolar, o que pode ser verificado nas Diretrizes Curriculares Nacionais Gerais da Educação Básica, que faz referência à Lei de Diretrizes e Bases da Educação Nacional, cujo Artigo 26 destaca a obrigatoriedade da Música como conteúdo no ensino da arte da base nacional comum nos níveis da educação básica, sendo considerado um meio para o desenvolvimento cultural dos alunos (BRASIL, 2013b).

\footnotetext{
A base nacional comum constitui-se de conbecimentos, saberes e valores produzidos culturalmente, expressos nas políticas públicas e gerados nas instituições produtoras do conbecimento cientifico e tecnológico; no mundo do trabalho; no desenvolvimento das linguagens; nas atividades desportivas e corporais; na produção artística; nas formas diversas de exercício da cidadania; e nos movimentos sociais (BRASIL, 2013b).
}

No âmbito da Educação Infantil, as já citadas Diretrizes Curriculares consideram a abordagem da Música como uma das experiências de promoção da aprendizagem das crianças que devem ser realizadas com regularidade e que contribui como uma das formas de expressão a serem realizadas, pois abrem possibilidades de vivências e desenvolvimento para as crianças. 
Dessa forma, as práticas pedagógicas inseridas na proposta de currículo para a Educação Infantil devem garantir experiências que "promovam o relacionamento e a interação das crianças com diversificadas manifestações de música” (BRASIL, 2013b).

Em relação ao Ensino Fundamental, é destacado que com a exposição das crianças e adolescentes à mídia, em particular a televisão, faz com que sejam desenvolvidas novas formas de expressão para as quais a linguagem universal que a maioria das crianças compartilha é a Música. A Educação Musical continua tendo importante papel na formação escolar como parte dos componentes curriculares obrigatórios do Ensino Fundamental.

E essa importância continua sendo refletida nas Diretrizes Curriculares Nacionais para o Ensino Médio, para a Educação Escolar Indígena, na Educação Escolar Quilombola e na Educação das Relações Étnico-Raciais e para o Ensino de História e Cultura Afro-Brasileira e Africana, instituída pela Lei 10.639/2003 “que estabelece a obrigatoriedade do ensino de História e Cultura Afro-Brasileira e Africana na Educação Básica" (BRASIL, 2013b). Com esta breve contextualização da educação musical no Brasil, torna-se necessário aprofundar-se mais no objeto desta pesquisa a partir de uma breve apresentação do jogo como recurso educacional, para em seguida tratar do uso do jogo digital na Educação e, finalmente, na Educação Musical.

\section{O Jogo Na Educação}

Antes ainda de citar alguns desses trabalhos relativos ao uso do jogo digital na Educação, é importante dizer que o jogo como estratégia educacional também foi e é amplamente estudado nos campos relacionados à Educação, como a Pedagogia e outros. Rau (2011) mostra que vários profissionais da área educacional fazem uso de jogos e brincadeiras como recursos pedagógicos, pois servem de auxílio no estabelecimento de relações entre os conteúdos e o mundo do aluno. Os elementos dos jogos, como a existência de regras, a interação com o meio e com os objetos e o uso das linguagens contribuem para a aprendizagem do aluno e seu consequente desenvolvimento. Para Cória-Sabini e Lucena (2004) é possível usar jogos como atividades didáticas, desde que o professor tenha consciência dos objetivos didáticos do jogo. Cita como exemplos jogos em que há contagem de pontos para determinar. Nesses casos, o professor pode usar os jogos para abordar o conceito de números ou as operações básicas. As autoras ainda mostram que os jogos permitem que as crianças desempenhem papeis ou tarefas específicas para realização de um objetivo comum, fazendo uso da cooperação e possa desenvolver melhor as interações e sua autonomia.

Ao tratar especificamente do uso de jogos como estratégia para a Educação Matemática, Ribeiro (2008) destaca que uma 
atividade inerente ao jogo é a resolução de problemas, o que está diretamente ligado ao contexto educativo das aulas de Matemática e pode tornar essas atividades motivadoras, prazerosas e desafiadoras. Ressalta que para isso é necessário um estudo minucioso dos jogos que se pretende propor aos alunos e das estratégias a adotar.

E acrescenta que o uso criterioso dos jogos pode representar a possibilidade de desenvolvimento de alunos críticos, inventivos, criativos e mais entusiasmados, além de contribuir para o exercício constante da autonomia.

No ensino da Química e da Biologia, Fialho (2013) traz o problema do desinteresse do aluno que é atribuído à falta de motivação proporcionada pelas metodologias de ensino baseadas em conceitos conservadores, que ainda privilegiam a transmissão de conhecimentos fragmentados e, especialmente em relação a essas duas disciplinas, a autora mostra que são desenvolvidas sem a devida contextualização e distantes da prática.

A utilização dos jogos nessas duas disciplinas, continua a autora, permite trazer ao ambiente educacional situações que permitam potencializar o aprendizado por meio da construção do conhecimento, que facilitem a compreensão dos conteúdos e que acabem por motivar os alunos para a aprendizagem de uma forma significativa e participativa.
Dois pontos considerados fundamentais pela autora para uma boa utilização dos jogos como ferramentas de aprendizagem são o cuidado com a clareza das regras - que representam o elemento marcante de um jogo educacional -, sem o que pode haver indisciplina e até mesmo questionamentos indevidos por parte dos alunos, descaracterizando a importância do jogo e da intenção proposta.

O outro ponto é a necessidade do professor conhecer bem seus alunos, considerando-os como agentes do processo de aprendizagem e como pessoas capazes de aprender, com suas capacidades, limitações, interesses e ritmos próprios, mas que podem ser incentivados a aprender desde que instigados a tanto.

\section{O Jogo Digital Na Educação}

Com o aumento da importância e da utilização de tecnologias de informação e comunicação pela sociedade e principalmente pela facilidade com que as crianças e adolescentes demonstram com essas tecnologias, vem sendo desenvolvidos diversos trabalhos acadêmicos. Cerca de 16.300 resultados foram obtidos em um recente levantamento realizado no Google Acadêmico a partir dos termos "videogame educação". O termo “jogos eletrônicos educação" gerou 
aproximadamente 15.100 resultados no mesmo site de busca.

Entre esses trabalhos pode-se citar o desenvolvido por Mattar (2010), que traz um estudo realizado no projeto New Media Literacies (NML) do Massachusetts Institute of Technology (MIT), listando habilidades e competências necessárias aos jovens para que estes possam participar plenamente do mundo atual. Entre essas habilidades e competências estão várias que são mais desenvolvidas nos momentos de lazer - com o jogo digital - ao invés de na escola.

$\mathrm{O}$ autor ainda destaca que existe um conflito de gerações na Educação, já que os alunos cresceram jogando jogos digitais, ao contrário de muitos de seus professores, embora pessoas de diversas faixas etárias também joguem. Coloca como um dos possíveis motivos para esse conflito um dos legados da era industrial, que é a diferenciação entre os espaços do trabalho e do lazer e que isso se refletiria na escola tradicional, pois não seria possível associar estudo a diversão. E faz referência a outros autores, como Alves (2004) que em seu estudo sobre violência e jogos digitais apresenta um extensivo levantamento da relação entre a educação e os jogos, do qual se pode citar que:

... a aprendizagem que é construída em interação com os games não se constitui em uma mera cópia mecânica das situações vivenciadas, mas na ressignificação que os jogadores fazem das imagens e ações presentes nos conteúdos dos jogos eletrônicos, mediante os seus modelos de aprendizagem construidos ao longo da sua estruturação como sujeito (ALVES, 2004).

Fadel et al (2014) apresentam o uso do jogo digital como estratégia para fomentar a motivação e o envolvimento em vários cenários educacionais, notadamente o escolar, sendo uma possibilidade de conexão da escola com o universo dos jovens por meio de desafios, fornecimento de recompensas e ranking, envolvendo os alunos emocional e cognitivamente. Destacam ainda o reconhecimento do jogo digital como produto audiovisual e a iniciativa "Geekie Games" do Ministério da Educação, uma plataforma online baseada em aprendizagem adaptativa e uso de desafios que pode ser utilizada pelos alunos interessados na preparação para o ENEM (Exame Nacional do Ensino Médio).

Lopes e Oliveira (2013) mostram que muitos jogos digitais exigem do jogador um conjunto de competências consideradas indispensáveis ao profissional do século XXI, como o pensamento estratégico, a capacidade de resolução de problemas, o desenvolvimento e implantação de planos de ação e adaptar-se a mudanças rápidas de situação.

Além disso, os jogos digitais permitem desenvolver habilidades como a comunicação, a interpretação e utilização de símbolos, capacidade de negociação, de tomar decisões coletivas e lidar com dados, além da melhoria de competências visuais, cognitivas e espaciais. 
Os autores ainda destacam que pesquisas no campo das neurociências tem mostrado que jogadores de jogos digitais apresentam melhores resultados se comparados a não jogadores no que se refere à acuidade e memória visual, percepção e atenção, entre outros atributos.

Também as habilidades de socialização de jogadores de jogos digitais foram apontadas pelos autores como sendo beneficiadas a partir de entrevistas realizadas com universitários, que "consideram que os videojogos favorecem as relações sociais, descrevendo-se como pessoas felizes, sociáveis, populares, simpáticas, extrovertidas, comunicativas e com muitos amigos.” (LOPES; OLIVEIRA, 2013).

Teixeira (2013) destaca que jogos digitais podem ser úteis em termos educacionais ao ajudarem a resolver problemas ou trazerem situações contextualizadas nas quais a motivação pode tornar mais dinâmico o processo de aprendizagem e cita como exemplos alguns jogos de combate e estratégia como a série $A g e$ of Empires e Sid Meier's Civilization, pois nesses jogos "podemos aprender muito sobre os costumes dos diversos povos envolvidos, os seus territórios e gentes, hábitos, questões sociais e políticas" (TEIXEIRA, 2013).

E o autor conclui dizendo que os jogos digitais podem ser bons ou maus de acordo com o uso que deles se fizer e que podem ser utilizados como um novo meio para a educação e como uma "caixa de ferramentas educacional e de aquisição de competências" (TEIXEIRA, 2013).
Para Fernandes (2010), os jogos digitais são recursos que podem ser utilizados como ferramentas para qualquer disciplina, devendo passar por uma análise criteriosa para que se possa definir os objetivos pedagógicos a serem alcançados e que sua utilização não pode ser vista como uma tentativa de substituir o docente.

Além disso, ressalta a necessidade do planejamento das atividades educacionais para que o jogo digital possa ser inserido de forma contextualizada, como uma forma de facilitar o aprendizado e não para agradar aos alunos.

O autor ainda traz a visão de que muitos educadores não reconhecem os jogos digitais como ferramentas educacionais, até por temor de que os alunos encarem sua disciplina ou suas aulas como algo figurativo. Mas, ao mesmo tempo, mostra que o entusiasmo demonstrado pelos alunos tem feito com que muitos professores têm sido motivados a utilizar os jogos digitais em suas aulas.

\section{O Jogo Digital E A Educação Musical}

A exemplo de outras disciplinas, a Educação Musical tem sido objeto de pesquisas desenvolvidas por brasileiros, algumas das quais serão apresentadas nesta seção do trabalho. Faria e Oliveira (2011) estudaram o jogo digital como estímulo para aprendizagem musical utilizando como exemplo o jogo Let's Tap que pode ser jogado na plataforma Nintendo Wii. Em seu 
estudo, as autoras verificaram que o jogo aborda de maneira clara os dois parâmetros do som enfatizados, que são a intensidade e o ritmo e que, embora com limitações, trata-se de um jogo que pode contribuir para o ensino de Música.

Nogueira (2009) mostra que a série Guitar Hero, apesar de não ser classificada como jogo digital educacional para Música, permite uma experiência que pode ter ênfase na categoria cognitiva, uma vez que o jogador precisa ter um conhecimento prévio do universo do rock e com isso possa identificar que determinadas músicas podem ser mais fáceis de tocar do que outras. Nesse caso o autor comparou uma música dos Ramones (compuseram usando apenas três acordes de guitarra) com outra do Queen (de bem maior complexidade). Assim, um jogo digital como Guitar Hero poderia contribuir para a formação de uma cultura auditiva.

Ainda sobre Guitar Hero, Aliel e Gohn (2012) trouxeram dados de uma pesquisa realizada com 509 jogadores dessa série de jogos digitais, segundo a qual 79\% dos jogadores indicaram ter aumentado sua predileção por novas músicas do estilo musical do jogo digital em questão.

Os autores ainda destacam que com o lançamento de Rock Band 3 passou a ser possível utilizar um sequenciador MIDI para capturar as notas produzidas com instrumentos reais, aumentando as possibilidades de usar o jogo digital em atividades educacionais de Música.
Um outro exemplo interessante destacado pelos autores é JoyTunes, cuja missão é "resolver um problema de $85 \%$ da população que 'gostaria de aprender a tocar um instrumento', mas nunca ultrapassaram os primeiros passos frustrantes do aprendizado" (JOYTUNES, 2013).

Como parte dessa missão, os desenvolvedores criam jogos digitais controlados por instrumentos musicais verdadeiros e para isso contam com educadores musicais, desenvolvedores de jogos digitais, músicos e designers gráficos em sua equipe. Há jogos para alunos iniciantes, de nível intermediário ou avançado.

A Universidade Federal de São Carlos possui um site com diversos jogos digitais e apps desenvolvidos, que podem ser acessados on-line ou em dispositivos que utilizam o sistema operacional Android, como diversos tablets de baixo custo ou smartphones. As Figuras 1, 2 e 3 a seguir mostram as telas de abertura de alguns desses jogos.

Figura 1. Tela inicial do jogo "Analisador de Acordes"

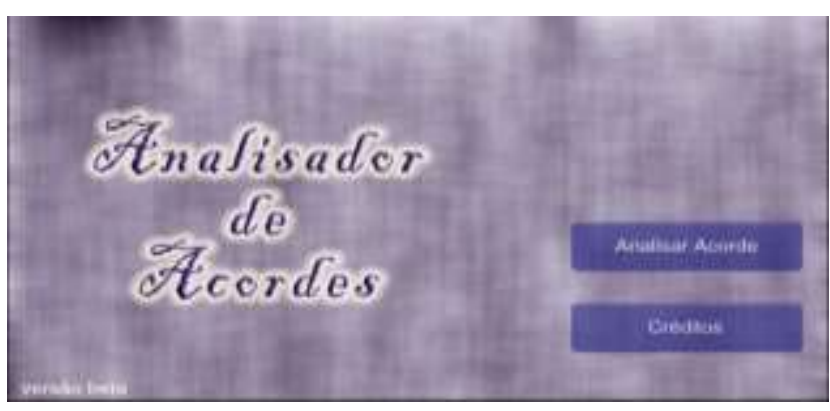

(fonte:

http://educacaomusical.sead.ufscar.br/jogos/) 
Figura 2. Tela inicial do jogo “O Incrível Músico das

Neves"

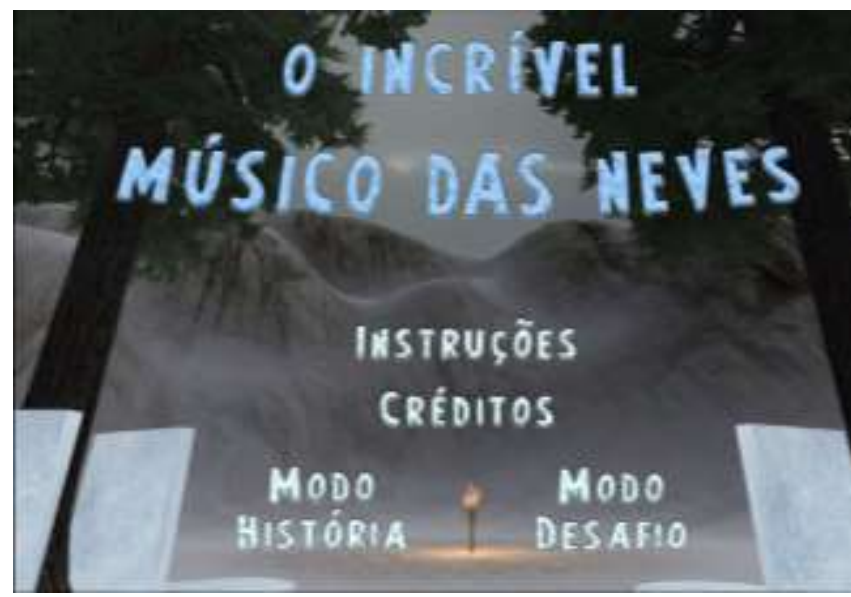

Fonte: http://educacaomusical.sead.ufscar.br/jogos.

Figura 3. Tela inicial do jogo "Uma Odisseia de Acordes"

\section{Uma Odisseia de Acordes}

Como noticiado pela Agência Fapesp (2012), os jogos são principalmente voltados aos alunos de Licenciatura em Música e Licenciatura em Educação Musical (oferecido à distância), mas podem ser acessados por qualquer interessado. Apresentam níveis de dificuldade crescente e uma seção de fundamentos para que o jogador possa se aprofundar na teoria musical abordada.

http://educacaomusical.sead.ufscar.br/jogos.
A Tabela 1 a seguir relaciona esses softwares dedicados à Educação Musical, que podem ser encontrados em http://educacaomusical.sead.ufscar.br/jogos. 
Tabela 1. Jogos e apps encontrados no site do curso de Educação Musical da UFSCar

\begin{tabular}{|c|c|}
\hline Título & Descrição \\
\hline Analisador de Acordes & $\begin{array}{l}\text { É uma app que pode ser explorada pelo usuário para realizar a análise harmônica } \\
\text { de acordes em tonalidades maiores. }\end{array}$ \\
\hline Escalas Musicais & Não há descrição no site. \\
\hline $\begin{array}{l}\text { O Incrível Músico das } \\
\text { Neves } 2.0\end{array}$ & $\begin{array}{l}\text { É um jogo que trabalha conceitos musicais. Apresenta os temas: intervalos } \\
\text { harmônicos e tríades maiores, menores, aumentadas e diminutas. }\end{array}$ \\
\hline T-Acordes $\left({ }^{*}\right)$ & $\begin{array}{l}\text { É uma app que trabalha a montagem de acordes em tríades e tétrades. O usuário } \\
\text { escolhe a raiz do acorde a ser construído e na sequência indica quais intervalos de } \\
\text { Terça, Quinta e Sétima ele deseja, ou ainda, quais notas ele deseja que componham } \\
\text { o acorde, obtendo ao final a cifra do acorde resultante. }\end{array}$ \\
\hline T-Escalas $\left({ }^{*}\right)$ & $\begin{array}{l}\text { É uma app que trabalha a leitura e percepção de escalas musicais. Possui: Escala } \\
\text { Maior/Menor, } 3 \text { Menores, Modos Gregos, Especiais, entre outros. }\end{array}$ \\
\hline T-Intervalos $(*)$ & $\begin{array}{l}\text { É uma app que trabalha a leitura e percepção de intervalos musicais. Possui: } \\
\text { Tom/Semitom, Classificação Básica/Completa, Simples/Compostos, entre outros. }\end{array}$ \\
\hline T-Notas $\left({ }^{*}\right)$ & $\begin{array}{l}\text { É uma app que trabalha a leitura e memorização de notas na partitura. Possui: } \\
\text { Linhas, Espaços, Linhas Suplementares e } 4 \text { opções de Clave. }\end{array}$ \\
\hline $\begin{array}{l}\text { Uma Odisseia de } \\
\text { Acordes }\end{array}$ & Não há descrição no site. \\
\hline
\end{tabular}

Fonte: http://educacaomusical.sead.ufscar.br/jogos. (*) Esses jogos ou apps possuem versões standalone para Windows e Mac que permitem jogar sem a necessidade de conexão à Internet.

Uma outra iniciativa no campo da Educação Musical é o Portal EduMusical, desenvolvido pelo Núcleo de Aprendizagem, Trabalho e Entretenimento do Laboratório de Sistemas Integráveis da Escola Politécnica da Universidade de São Paulo, cujo desenvolvimento foi descrito por Ficheman et al (2004).

O portal permite aos interessados encontrarem aplicativos para a aprendizagem musical, como jogos de apreciação musical, reconhecimento de timbres, reconhecimento de notas musicais e outros. Ainda dispõe de ferramentas de comunicação entre os usuários, que incluem alunos, professores, especialistas em Educação Musical e a equipe de desenvolvimento.

$$
\text { O acesso ao portal é livre, sendo }
$$
necessário apenas um breve cadastramento a partir de http://edumusical.org.br. A Figura 4 a seguir ilustra a página inicial do EduMusical. 
Figura 4. Página inicial do portal EduMusical

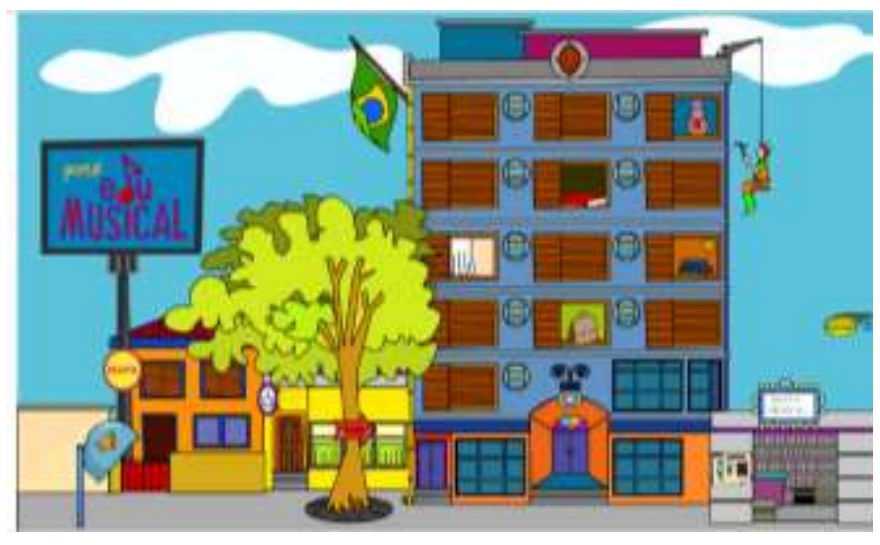

Fonte: http://edumusical.org.br

No desenvolvimento do projeto participaram especialistas de diversas áreas, como Computação, Engenharia, Música, Comunicação Visual e Jornalismo, além de crianças que representavam o público-alvo do portal, fundamentais nas fases de teste e adequação do conteúdo às necessidades e expectativas dos usuários.

Um dos jogos disponíveis no portal é o Jogo da Memória, com cartas que possuem imagens de instrumentos e outras com seus respectivos sons. O objetivo é associar os instrumentos aos sons, contribuindo para $\mathrm{O}$ reconhecimento de timbres. Além desse, o portal conta com outros jogos como o Jogo da Oficina de Instrumentos, o Jogo do Piano, o Jogo dos Instrumentistas e o Jogo do Quebra-Cabeça Musical.

O EduMusical tem como um dos objetivos mostrar que é possível utilizar Augusto Guzzo Revista Acadêmica, 2015, №15, 74-91 computadores nas escolas para melhorar a criatividade, uma vez que o aluno pode criar sem executar repetições. O portal foi testado em ONGs, em escolas e na Feira de Ciências e Engenharia (Febrace), segundo a coordenadora do projeto, e busca parcerias para maior divulgação. (KANNO, 2004).

Segundo o I Censo da Indústria Brasileira de Jogos Digitais [BNDES 2014], no ano de 2013 foram desenvolvidos 621 jogos educacionais no Brasil por 133 empresas, cerca de 44\% do total de títulos produzidos, sendo que apenas uma das empresas foi responsável pelo lançamento de 117 jogos educacionais. No entanto, não existe um diretório ou lista de jogos digitais educacionais desenvolvidos por empresas brasileiras, o que dificulta um trabalho de análise mais acurada acerca dos títulos disponíveis ou até mesmo de simples apresentação desses jogos digitais.

\section{Considerações Finais}

A Educação Musical, seja no sistema formal ou nas iniciativas não-formais, traz diversos benefícios para o desenvolvimento do ser humano em suas fases da vida. Nesse sentido, as políticas públicas educacionais brasileiras têm dado um maior espaço para o ensino de Música, principalmente na Educação Básica, que inclui os Ensinos Fundamental e Médio.

www.fics.edu.br 86 
Uma das estratégias educacionais utilizadas em disciplinas diversas é a adoção de jogos em seus devidos contextos. Diversas obras já foram publicadas sobre o assunto, bem como pesquisas acadêmicas tem sido desenvolvidas para que se possa aumentar a compreensão de como os jogos podem servir como auxílio aos professores no ensino das diversas disciplinas no ambiente escolar.

O uso de jogos digitais como ferramenta de apoio às atividades educacionais tem sido pesquisado e debatido por pesquisadores brasileiros de diversas áreas e pode-se dizer que existe uma percepção de que o jogo digital pode ser um aliado do professor na prática pedagógica, embora haja obstáculos ao uso desse recurso, principalmente pela possível falta de compreensão do jogo digital como ferramenta educacional.

E nesse sentido, embora existam jogos digitais brasileiros voltados à Educação Musical e um aparente interesse das empresas brasileiras de desenvolvimento de jogos digitais em produzir novos títulos, há uma lacuna de informação a respeito dos títulos disponíveis, fazendo com que educadores acabem utilizando jogos desenvolvidos por empresas estrangeiras, não adaptados à realidade educacional brasileira e às necessidades de alunos e professores.

Pode-se sugerir, como futuro desenvolvimento de pesquisa resultante desta, a realização de um levantamento junto às empresas brasileiras de desenvolvimento de jogos digitais para que se tenha informações sobre títulos voltados à Educação Musical e que esses títulos possam ser objeto de avaliações no sentido de verificar o quanto efetivamente contribuem para o aprendizado de Música.

\section{Referências Bibliográficas E Eletrônicas}

AGÊENCIA FAPESP. Jogos virtuais auxiliam no ensino de música. São Paulo: Fundação de Amparo à Pesquisa de São Paulo, 2012. Disponível em: http://agencia.fapesp.br/15625. Acesso em 29 mar. 2014.

ALIEL, L.; GOHN, D. Jogos eletrônicos musicais e EAD: contingência de ferramentas para aprendizagem instrumental. In: Anais do I SIED: EnPED - Simpósio Internacional de Educação a Distância e Encontro de Pesquisadores em Educação a Distância. São Carlos: Universidade Federal de São Carlos, 2012. Disponível em: http://www.siedenped2014.ead.ufscar.br/ojs/index.php/sied/arti cle/view/64/32. Acesso em 29 mar. 2014.

ALVES, L.R.G. Game Over: jogos eletrônicos e violência. Tese (Doutorado) - Programa de Pós-Graduação em Educação. Salvador: Universidade Federal da Bahia, 2004. Disponível em: 
http://www.lynn.pro.br/admin/files/lyn_artigo/ 685ef5af57.pdf. Acesso em 22 mar. 2014.

ARMELIATO. E. Jogos computacionais na educação: uma aplicação ao ensino de música. Dissertação (Mestrado) - Programa de Pós-Graduação em Engenharia Elétrica e de Computação. Campinas: Universidade Estadual de Campinas, 2011. Disponível em: http://www.bibliotecadigital.unicamp.br/docum ent/?down=000866955. Acesso em 29 mar. 2014.

BALBINOT, G. Educação não-formal: a contribuição da música para a educaşão da sensibilidade na adulter. Dissertação (Mestrado) - Faculdade de Educação da PUCRS. Porto Alegre: PUCRS, 2013. Disponível em: http://tede.pucrs.br/tde_busca/arquivo.php?cod Arquivo=4644. Acesso em 08 mar. 2014.

BNDES. I Censo da Indústria Brasileira de Jogos Digitais. Rio de Janeiro: Banco Nacional de Desenvolvimento Econômico e Social, 2014. Disponível em: http://www.bndes.gov.br/SiteBNDES/bndes/b ndes_pt/Galerias/Arquivos/conhecimento/semi nario/seminario_mapeamento_industria_games0 42014_RelApoioCensoIndustriaBrasileiradeJogos .pdf. Acesso em 02 abr. 2014.
BRASIL. Parecer CNE/CEB no 12/2013. Define Diretrizeses Nacionais para a operacionalização do ensino de Música na Educação Básica. Brasilia: Conselho Nacional de Educação. Câmara de Educação Básica, 2013a. Disponível em http://portal.mec.gov.br/index.php?option=co m_docman\&task $=$ doc_download\&gid $=14875 \& \mathrm{I}$ temid=. Acesso em 15 mar. 2014.

BRASIL. Diretrizes Curriculares Nacionais Gerais da Educação Básica. Brasilia: Ministério da Educação. Secretaria de Educação Básica. Diretoria de Currículos e Educação Integral, 2013b. Disponível em:

http://portal.mec.gov.br/index.php?option=co m_docman\&task $=$ doc_download\&gid $=13448 \& \mathrm{I}$ temid=. Acesso em 15 mar. 2014.

CHIARELLI, L.K.M.; BARRETO, S. de J. A importância da musicalização na Educação Infantil e no Ensino Fundamental: a Música como meio de desenvolver a inteligência e a integração do ser.In: Revista Recre@rte No3 Junio 2005 ISSN: 1699-1834. Santiago de Compostela: Instituto Avanzado de Creatividad Aplicada Total, 2005. Disponível em: http://www.iacat.com/Revista/recrearte/recrear te03/musicoterapia.htm. Acesso em 08 mar. 2014. 
CÓRIA-SABINI, M.A.; LUCENA, R.F. de. Jogos e brincadeiras na educação infantil. 5.ed. Campinas: Papirus, 2004.

CORREA, A.N. Bebês produzem Música? O brincarmusical de bebês em berçário. Tese (Doutorado) Programa de Pós-Graduação em Educação. Porto Alegre: Universidade Federal do Rio Grande do Sul, 2013. Disponível em: http://www.lume.ufrgs.br/ bitstream/handle/10183/72121/000882111.pdf. Acesso em 08 mar. 2014.

FADEL, L.M. et al (orgs.). Gamificação na educação. São Paulo: Pimenta Cultural, 2014.

FARIA, L.C.F. de; OLIVEIRA, P.L.L.M.G. de. O jogo eletrônico como estímulo de aprendizagem musical. In: Colloquium Humanarum, v. 8, n. Especial, jul.-dez. 2011. Presidente Prudente: Universidade do Oeste Paulista, 2011. Disponível em: http://www.unoeste.br/site/

pos/enapi/2011/suplementos/documentos/Hu manarum-PDF/CDA rtes. pdf. Acesso em 29 mar. 2014.

FERNANDES, J.C.L. Educação digital: Utilização dos jogos de computador como ferramenta de auxílio à aprendizagem. In: FaSCi-
Tech, v.1, n.3, jul./dez.2010, p. 88-97. São Caetano do Sul: Fatec São Caetano do Sul, 2010. Disponível em: http://www.fatecsaocaetano.edu.br/ fascitech/index.php/fascitech/article/view/28/2 7. Acesso em 22 mar. 2014.

FICHEMAN, I.K. et al. PORTAL EDUMUSICAL: Telemática aplicada à Educação Musical. In: Anais do XV Simpósio Brasileiro de Informática na Educação. Manaus: Universidade Federal do Amazonas, 2004. Disponível em: http://www.br-ie.org/pub/index.php/sbie/ article/view/351/337. Acesso em 29 mar. 2014.

FIALHO, N.N. Jogos no ensino de Química e Biologia. Curitiba: InterSaberes, 2013.

GOHN, M. da G. e STAVRACAS, I. O papel da Música na Educação Infantil. In: EccoS Revista Científica, vol. 12, núm. 2, jul.-dez: 2010, pp. 85-103. São Paulo: Universidade Nove de Julho, 2010. Disponível em: http://www.redalyc.org/pdf/715/71518580013. pdf. Acesso em 08 mar. 2014.

JANAUDIS, M.A. A música como instrumento de reflexão para o estudante de Medicina. Tese (Doutorado) - Programa de Pós-Graduação em 
Ciências Médicas. São Paulo: Universidade de São

Paulo, 2010. Disponível em: http://www.teses.usp.br/teses/disponiveis/5/51

69/tde-20052011-

175337/publico/MarcoAurelioJanaudis.pdf.

Acesso em 08 mar. 2014.

JOYTUNES. About JoyTunes. Tel Aviv: Joy'Tunes Ltd, 2013. Disponível em: http://www. joytunes.com/about.php. Acesso em 29 mar. 2014.

KANNO, M. Projeto Edumusical facilita a educação musical de crianças. São Paulo: Agência USP de Notícias, 2004. Disponível em: http://www.usp.br/agen/bols/2004/rede1433.h tm. Acesso em 29 mar. 2014.

LOPES, N. e OLIVEIRA, I. Videojogos, Serious Games e Simuladores na Educação: usar, criar e modificar. In: Educação, Formação e Tecnologias, vol. 6, n. 1. Monte da Caparica: Educom - Associação Portuguesa de Telemática Educativa, 2013. Disponível em: http://www.eft.educom.pt/index.php/eft/article /view/346/176. Acesso em 22 mar. 2014.
MATTAR, J. Games em educação: como os nativos digitais aprendem. São Paulo: Pearson Prentice Hall, 2010.

NOGUEIRA, B.P. Guitar Hero: novas práticas de consumo e cultura auditiva na música através dos videogames. In: Contemporanea - Revista de Comunicação e Cultura, vol. 7, n. 2, 2009. Salvador: Faculdade de Comunicação, Universidade Federal da Bahia, 2009. Disponível em: http://www.portalseer.ufba.br/index.php/conte mporaneaposcom/article/view/3698/2884.

Acesso em 29 mar. 2014.

OLIVEIRA, S.A.C. de. Um estudo sobre Música e qualidade de vida na terceira idade com base em princípios de Educação Ambiental. Tese (Doutorado) Programa de Pós-Graduação em Educação Ambiental. Rio Grande: Universidade Federal do Rio Grande, 2013. Disponível em: http://www.argo.furg.br/bdtd/0000010278.pdf. Acesso em 08 mar. 2014.

RAU, M.C.T.D. A ludicidade na educação: uma atitude pedagógica. 2.ed. Curitiba: Ibpex, 2011.

RIBEIRO, F.D. Jogos e Modelagem na Educação Matemática. Curitiba: Ibpex, 2008. 
TEIXEIRA, L.F.B. Cultura de simulação, videojogos e educação: uma (nova) caixa de ferramentas para a aprendizagem. In: Lumina, vol. 7, n. 1, jun. 2013. Juiz de Fora: Universidade
Federal de Juiz de Fora, 2013. Disponível em: http://www.lumina.jor.br/index.php/lumina/ article/view/72/153. Acesso em 22 mar. 2014. 